\title{
Atualização sobre endopróteses vasculares (stents): dos estudos experimentais à prática clínica
}

\author{
Update on vascular endoprostheses (stents): from experimental \\ studies to clinical pratice
}

Luís Henrique Gil França ${ }^{1}$, Adamastor Humberto Pereira²

\section{Resumo}

Atualmente, o tratamento das doenças vasculares periféricas é uma das áreas da medicina de maior expansão. O número de intervenções vasculares aumenta e os resultados das novas técnicas endovasculares estão muito próximos aos das tradicionais cirurgias vasculares. Embora a angioplastia ofereça bons resultados em curto prazo, o implante de stents procura melhorar o sucesso do procedimento e estender o seu uso a um número maior de pacientes com doença vascular periférica. Entretanto, a sua utilização ainda é controversa. O implante de stents no sistema aorto-ilíaco tem bons resultados; porém, a sua indicação para as lesões femoro-poplíteas ainda é discutida. Além disso, o rápido desenvolvimento de stents e sua escolha para uso no sistema vascular periférico têm sido uma difícil tarefa para o cirurgião endovascular. Muitos fatores influenciam a escolha do stent, e um amplo conhecimento desse material é essencial. Tal escolha depende da avaliação pré-operatória, da localização e das características da lesão e também do uso do stent primário ou seletivo. Nesse trabalho, são realizadas revisão do histórico do desenvolvimento dos stents, desde os estudos experimentais até os ensaios clínicos e também discussão sobre a sua aplicação no tratamento das doenças vasculares periféricas.

Palavras-chave: Artéria, prótese vascular, doenças vasculares periféricas.

\section{Introdução}

Stents são estruturas tubulares metálicas, em forma de malha, inseridas na luz vascular, cuja função é manter o lúmen arterial aberto (por meio de pressão mecânica) e evitar as reestenoses decorrentes do desenvolvimento da hiperplasia intimal ou da contração resultante do tratamento de lesões fibroelásticas ${ }^{1}$. O termo "stent" vem do epônimo Charles Thomas Stent (1807-1885), dentista que criou um material moldável

\begin{abstract}
The treatment of peripheral vascular diseases is one of the most rapidly expanding fields of medicine today. The number of peripheral interventions increased and innovative endovascular techniques are close to the results of traditional vascular surgeries. Although balloon angioplasty alone offers good immediate results, implantation of stents has been proposed to improve the procedural success and extend its application to more patients with peripheral vascular disease. However, stenting is controversial. Use of stents has good results in aortoiliac vessels, but its use in femoropopliteal vessels is still in dispute. Moreover, the rapid development of endovascular stents for peripheral applications and their choice have been a complicated task for endovascular surgeons. Many factors influence choice of stent, therefore, knowledge of available stents is mandatory. Appropriate selection depends on adequate preprocedural evaluation of the lesion, choice of primary vs. selective stent placement, and location and characteristics of the lesion. In this article the history of stent development is reviewed, from studies with experimental models to clinical practice, and its application in the treatment of peripheral vascular diseases is discussed.
\end{abstract}

Keywords: Artery, vascular graft, peripheral vascular diseases.

com a finalidade de manter em posição enxertos de pele na cavidade oral. Em relação à opção pela forma de inserção, classificam-se em: stent direto (implante do dispositivo antes da dilatação por balão), stent primário (inserção pré-determinada após ATP) e implante seletivo de stent (inserção após resultado subótimo da ATP). A maioria dos stents é implantada de forma seletiva, sendo indicado em estenose residual, recuo elástico, resultado ruim com gradiente pressórico, complicações como dissecção ou "flap" intimal, ulcerações de placa,

1. Doutor em Cirurgia, Universidade Federal do Rio Grande do Sul (UFRGS), Porto Alegre, RS. Mestre em Clínica Cirúrgica, Universidade Federal do Paraná (UFPR), Curitiba, PR. Especialista em Cirurgia Vascular, Cirurgia Endovascular e Angiorradiologia (SBACV/CBR/AMB).

2. Professor adjunto. Chefe, Serviço de Cirurgia Vascular, Hospital de Clínicas de Porto Alegre (HCPA), Porto Alegre, RS.

Não foram declarados conflitos de interesse associados à publicação deste artigo.

Artigo submetido em 24.05.08, aceito em 15.10.08.

J Vasc Bras. 2008;7(4):351-363.

Copyright@ 2008 by Sociedade Brasileira de Angiologia e de Cirurgia Vascular 
oclusões e reestenose. Já o stent primário pode ser empregado em caso de oclusões, lesões de alto risco para reestenose e lesões maiores que $8 \mathrm{~cm}$, difusas, excêntricas ou ulceradas. Seu uso é limitado em casos de tortuosidade acentuada do vaso e lesões muito calcificadas ${ }^{1-3}$.

Os stents podem ser distinguidos por vários fatores, como: o mecanismo de implante (auto-expansivo, balão expansivo ou memória térmica), a geometria (formato dos anéis - "células abertas ou fechadas"), o tipo de malha formada pelas hastes de metal, o seu desenho estrutural (tubular ou mola) e sua composição metálica ${ }^{4}$.

Os stents auto-expansivos vêm comprimidos por fina membrana de plástico sobre cateter de pequeno calibre (exemplo: Wallstent ${ }^{\circledR}$ ) ou vêm comprimidos no interior de cateteres de maior diâmetro (exemplo: Craggstent ${ }^{\circledR}$ ). Ao serem daí ejetados, expandem-se para o diâmetro da luz do vaso previamente dilatado, por um balão de angioplastia, para seu diâmetro normal. Esses stents possuem alta flexibilidade, o que permite a expansão a um limite predeterminado, após a remoção da bainha introdutora. Eles são relativamente fáceis de implantar; porém, apresentam pequena resistência à compressão radial. Podem sofrer encurtamento e não são liberados com muita precisão como os expansíveis por balão. Tais stents estão indicados nas seguintes localizações: eixos aorto-ilíaco e femoro-poplíteo, carótidas e lesões nãoostiais da artéria subclávia ${ }^{4,5}$.

Os stents expansíveis por balão são colocados com maior precisão e apresentam boa resistência à compressão radial; entretanto, possuem pouca elasticidade e pouca flexibilidade longitudinal, podendo ser reinflados com um balão maior. Devido à alta força radial, esses stents têm preferência em lesões ostiais e em locais com calcificações e com compressão externa. Os locais contra-indicados para tais stents são os próximos às articulações, em volta de ossos e ligamentos e junto a pontos de flexão. Eles se abrem normalmente das pontas para o centro de maneira a se fixarem na parede. Então, o deslocamento do material da parede se faz da periferia para o centro da lesão, diminuindo a chance de embolização. Assim, tais stents estão indicados nas seguintes localizações: eixo aorto-ilíaco, artérias renais, lesões ostiais da artéria subclávia e lesões orificiais dos troncos supra-aórticos. Exemplos: Palmaz (Cordis), Strecker (Medi-tech) $)^{4,5}$.

As diferenças e vantagens entre stents autoexpansíveis e expansíveis por balão são amplamente estudadas em modelos experimentais. Chuapetcharasopon et al., implantaram stents expansíveis por balão e stents auto-expansíveis em artérias ilíacas de suínos submetidos à dieta aterogênica. $\mathrm{O}$ resultado foi uma hiperplasia intimal muito mais acentuada no grupo em que foram utilizados os stents expansíveis por balão. Tal resultado foi atribuído ao maior trauma da parede vascular pela expansão do balão ${ }^{6}$. Mangell et al. compararam a utilização desses dois tipos de stents no crescimento de aorta de porcos por um período de 4 a 18 semanas $^{7}$. O peso dos porcos aumentou de uma média de 20 para $93 \mathrm{~kg}$ e o diâmetro da aorta dos animais aumentou $60 \%$. Os stents expansíveis por balão não mostraram movimento pulsátil e estavam sujeitos ao descolamento da parede do vaso, ao passo que os stents auto-expansíveis seguiram a mudança de diâmetro do vaso sem afetar a expansibilidade após 18 semanas, além da boa fixação, apesar da dilatação do vaso. Andrews et al. implantaram stents auto-expansíveis próximos à articulação coxo-femoral em artérias e veias femorais de suínos e concluíram que esses stents, quando colocados em regiões de articulação e em veias, têm risco maior de desenvolver hiperplasia intimal e, eventualmente, oclusão em comparação àqueles colocados em vasos com pouca mobilidade e em artérias $^{8}$.

Os stents com expansão térmica assumem seus formatos originais após exposição à temperatura corporal. O protótipo é o stent de nitinol, tendo como exemplos: Cragg Nitinol (Mintec), Memotherm (Angiomed Bard) e VascuCoil (Medtronic) ${ }^{4}$.

Alguns autores destacam as propriedades ditas ideais de um stent intravascular, tais como: alta opacidade para melhor visualização, facilitando o implante; grande força radial para resistir ao remodelamento elástico; mínima variação de formato depois de implantado para aumentar a precisão; sistema de implante simples e de fácil manuseio; flexibilidade longitudinal para cruzar vasos tortuosos e bifurcação aórtica; elasticidade radial 
para resistir à compressão externa sem deformação permanente, sobretudo em locais de articulação; pequeno perfil com grande expansão para passar por pequenos introdutores e estenoses críticas; mínimo encurtamento após a liberação; fácil resgate para o caso de falha na implantação; ramo lateral acessível; mínima indução de hiperplasia intimal; resistência à trombose e à corrosão; e durabilidade e baixo preço ${ }^{5,9,10}$.

O comportamento biomecânico e o desenho do stent têm efeito importante nas respostas do hospedeiro à presença do stent. A distensibilidade radial e a flexibilidade longitudinal afetam a perviedade dos stents a longo prazo. Um aumento na complacência e na flexibilidade pode ter efeito negativo pela estimulação da atividade fibromioblástica e pela interferência com a endotelização ${ }^{4}$.

A arquitetura dos stents é composta de anéis que podem ser tanto montagem individual como acumulação seqüencial em um padrão de repetição. Os anéis individuais podem ser simplesmente acoplados uns aos outros, de modo similar ao stent Gianturco Z (Cook). Esse tipo é utilizado atualmente em endopróteses e para vasos de grosso calibre, como a veia inominada e a veia cava superior. O outro tipo é a junção seqüencial de anéis, utilizando uma variedade de conexões que também conferem propriedades aos stents. Os espaços entre os anéis são chamados de células, que podem ser fechadas (os elementos estão muito ligados, como "favo de mel”) e abertas (as conexões são deixadas abertas). O stent de Palmaz original é um tubo cortado a laser, um balão expansível que cria uma rede de quatro células fechadas. Tais células são conectadas entre si geometricamente através de conectores não-flexíveis. $\mathrm{O}$ resultado é geometricamente simples e produz uma estrutura forte e durável em áreas que não estão sujeitas às forças de quebra ou que demandam flexibilidade. Essa falta de flexibilidade pode causar problemas não apenas em áreas de tortuosidade mas também em alvos retos com acessos difíceis (ilíaca contralateral no caso de uma bifurcação aórtica com ângulo muito agudo). Mesmo se uma bainha consegue ser colocada com sucesso, o stent pode não ter capacidade de avançar através da torção da bainha ${ }^{4,5}$. Os primeiros "conectores flexíveis", desenhados por Palmaz e Schatz eram fios metálicos retos e simples entre segmentos de células que conferiram um grau de flexibilidade entre seqüências de segmentos inflexíveis da rede de células, semelhantes às conexões de vagões de trem ${ }^{11}$. A geometria específica da conexão, por si só, concede grau de flexibilidade longitudinal, radial e de torção. Atualmente, existe grande variedade de tipos de conectores que se esticam em qualquer direção, não apenas em resposta à expansão pelo balão, mas também à tortuosidade e irregularidade do vaso. Geralmente, os stents com células fechadas têm a vantagem de obter uma cobertura mais uniforme do vaso, e os com células abertas têm uma maior flexibilidade; porém, esses provêem menor suporte, com chance de cobertura inadequada, especialmente em vasos tortuosos, nos quais a torção do stent torna algumas células mais abertas que outras ${ }^{4}$.

Os stents com malha do tipo "trançada" (braided stents), como, por exemplo, o Wallstent, apresentam boa visibilidade, flexibilidade e, antes da liberação total, têm a vantagem de recolhimento de até $87 \%$ do stent no dispositivo; as desvantagens incluem: encurtamento e a dissecção intimal causada pelo alargamento dos limites distais do stent, se o dispositivo de liberação for empurrado inadvertidamente durante a liberação ${ }^{12}$; embora sejam flexíveis, esses stents possuem bastante rigidez, tanto que, em superfícies irregulares, o stent não se amolda bem, mas se alarga gradualmente, deixando espaço entre o stent e a parede arterial (baixa conformidade). Uma melhor conformidade do stent com a parede arterial pode reduzir a reestenose. Rolland et al. demonstraram que ao colocar stents de conformidade adaptada ao vaso (compliance matching stent) em carótidas de suínos, a taxa de reestenose foi menor ${ }^{13}$. Atualmente, quando se utilizam stents auto-expansíveis, recomenda-se sempre utilizar os de nitinol cortados a laser, que apresentam um encurtamento de menos de $3 \%$. Os de nitinol trançados apresentam um encurtamento que pode alcançar até $50 \%$ do comprimento original do stent, quando dentro da bainha de liberação ${ }^{1,4,5}$.

Os stents também podem ter a forma de espiral (coil stent) que minimiza o recuo elástico e sela os pontos de dissecção. Sua melhor utilização são os pontos de flexão, como as lesões localizadas na artéria poplítea, atrás 
do joelho. Não foi relatada melhora estatisticamente significativa na taxa de revascularização em 9 meses quando comparado com a ATP. Entretanto, foi relatada melhora significativa no índice tornozelo/braquial e baixa taxa de complicação com seu uso ${ }^{14}$. A escolha do melhor stent a ser utilizado em cada caso depende da anatomia arterial e da morfologia da lesão. Na presença de anatomia tortuosa, os stents com células abertas e mais flexíveis têm preferência. Quando existe uma diferença de diâmetro significativa entre a artéria carótida comum e a interna, são selecionados stents de cobalto-cromo (Elgiloy), ou stents cônicos de nitinol. Lesões com alto potencial emboligênico são tratadas com stents com a configuração de células fechadas, enquanto que lesões muito calcificadas necessitam ser tratadas com stents de nitinol ${ }^{15}$.

Os stents podem ser confeccionados em diversos materiais, como o aço inoxidável 304 SS, 316 L SS, tântalo, elgiloy (SS), platina, liga de cobalto e nitinol ${ }^{4}$. Dyet $\&$ Schurmann citam que os stents de aço inoxidável da série $316 \mathrm{~L}$ apresentam boa biofuncionalidade, (grau que o metal se adapta para exercer determinada função) e boa biocompatibilidade (grau que o metal permanece inerte após ser implantado no sistema arterial sem provocar reação do tipo corpo estranho ou liberar íons tóxi$\cos )^{16}$. Gotman expõe que os stents de aço inoxidável são constituídos de uma liga composta de ferro, cromo e manganês, possuindo também traços de outros metais, como, por exemplo, molibdênio, manganês, cobre e carbono. Apesar de esses outros elementos constituírem pequena amostra do total, podem alterar tanto a estrutura cristalina do metal como as propriedades da liga metálica ${ }^{17}$. Um dos mais importantes constituintes dos dispositivos de aço inoxidável utilizados para fins médicos é o cromo. Uma concentração de pelo menos $12 \%$ de óxido de cromo é necessária para revestir a superfície externa do metal, com o intuito de evitar a corrosão a que o metal está exposto na corrente sanguínea ${ }^{16,17}$.

O nitinol é uma liga de níquel e titânio com propriedades de memória térmica, que permite ser compactado firmemente dentro de um sistema de liberação quando esfriado, para se expandir rapidamente e readquirir seu formato e seu tamanho pré-designados, após a liberação de seu sistema de colocação na corrente sanguínea. Além disso, possui grande elasticidade e resistência à fratura. Nitinol é a sigla de Nickel Titanium Naval Ordinance Laboratories, cuja liga metálica foi inicialmente desenvolvida para fins militares ${ }^{18}$. Entretanto, em stents de nitinol ocorre a liberação de níquel, que é um dos responsáveis pela hiperplasia intimal. $\mathrm{O}$ níquel é um componente normal da dieta, mas sua exposição a níveis elevados pode acarretar sérios problemas respiratórios, reações alérgicas locais e sistêmicas e inibição da reprodução celular. Por outro lado, o titânio aparenta ser inerte. O níquel e o titânio formam uma liga metálica extremamente forte, sendo o nitinol resistente a oxidação do níquel, o qual poderia liberar íons desse metal e aumentar o risco de reações adversas. Da mesma forma que os stents de aço inoxidável, os de nitinol, quando implantados dentro do sistema vascular, ficam recobertos por uma fina camada de óxido. Nesse caso, entretanto, forma-se o óxido de titânio que estabiliza a superfície interna do stent e previne assim a reação dos íons níquel com os tecidos do corpo humano ${ }^{18}$. A fratura de stents de nitinol pode estar relacionada ao polimento e ao revestimento da superfície do stent com óxidos amorfos ${ }^{19,20}$.

Uma série de processos celulares e moleculares contribui na cicatrização intravascular dos stents. Tal processo de cicatrização reflete uma resposta programada, tipo corpo estranho, à implantação no sistema vascular e resulta em quatro tipos de tecido: trombo, neo-íntima, endotélio e infiltrado de células inflamatórias. A localização e a extensão de cada tipo desses quatro tecidos são influenciadas por vários fatores relacionados ao próprio implante da endoprótese, como a localização da malha metálica do stent, o tipo de enxerto que o reveste, a microestrutura e a porosidade da endoprótese ${ }^{21}$.

A aspereza da superfície, a carga elétrica, a energia de superfície livre e a umidade são características físicas da superfície do stent com determinantes importantes de trombogenicidade e interações com o tecido. A lisura da superfície metálica é importante porque a torna menos trombogênica. A maioria das superfícies metálicas implantadas em humanos tem uma carga de superfície eletropositiva que atrai o fibrinogênio, formando, assim, uma fina camada após alguns segundos do 
implante do stent. Tal camada de fibrinogênio diminui a tensão superficial da superfície do metal, conferindolhe menos trombogenicidade. Nas primeiras semanas após o implante do stent, o trombo que circunda as hastes dos stents é gradualmente substituído pela hiperplasia intimal, e o número de novos vasos formados em cada área está relacionado com o número de células miointimais $^{22}$. Pisco estudou as reações que ocorrem após implante de stent em aorta de cães e demonstrou que tal neovascularização tem origem da vasa vasorum ${ }^{23}$. Em cães, a formação neo-intimal atinge seu limite após 2 meses do implante do stent e, conseqüentemente, começa a tornar-se mais fina, com poucas células e, aos poucos, vai sendo substituída por colágeno.

Imediatamente após a exposição de um dispositivo metálico à corrente sanguínea, uma série de eventos modifica sua superfície, com intenção de prepará-la para a colonização do tecido. A modificação da morfologia da parede arterial após o implante do stent apresenta uma seqüência bem definida de eventos. Inicialmente, ocorre a formação de trombos e o aparecimento de uma inflamação aguda logo após o implante e, posteriormente, o crescimento de neo-íntima. O aumento da inflamação, após o implante de stent, está associado à injúria da camada média e à penetração da malha do stent no núcleo lipídico ${ }^{22}$.

A porção metálica do stent também influencia a cicatrização. O esqueleto metálico é um importante determinador na formação do trombo que, por sua vez, serve de nicho para a formação de neo-íntima. Poucos segundos após o implante, ocorre depósito de fibrina e de outras proteínas plasmáticas na estrutura metálica exposta ao fluxo sanguíneo ${ }^{22}$. Nos primeiros 15 minutos de exposição do stent à corrente circulatória, verifica-se aderência de plaquetas e leucócitos à superfície do stent que está recoberto por fibrina, contribuindo para a formação do trombo inicial. O grau de trombo que se forma na malha do stent, nessa fase, exercerá grande influência no crescimento neo-intimal subseqüente ${ }^{24}$. Palmaz et al. demonstraram que, em 24 horas, já existe uma completa camada de fibrina na superfície do stent, com linhas orientadas na direção do fluxo sanguíneo. Os autores sugerem que as linhas de fibrina podem servir como estrutura para o desenvolvimento de células endoteliais ${ }^{25}$.

No momento do implante das endopróteses ocorre certo grau de lesão da parede vascular. Mesmo os stents auto-expansíveis necessitam de dilatação com balão para se acomodarem melhor à parede arterial. Os stents expansíveis por balão, por si só, necessitam de um cateter balão para se expandirem no sistema arterial, causando, às vezes, dano à parede arterial no momento do implante, com ruptura da camada média e da lâmina elástica interna. Quando ocorre lesão da camada média e a desproporção relativa do diâmetro do stent em relação à luz arterial, é relatada uma maior resposta da hiperplasia intimal ${ }^{21}$. Palmaz sugere que a expansão adequada do stent (geralmente de um diâmetro de 10 a 15\% maior que o do vaso) é necessária para garantir a incrustação das hastes do stent na parede do vaso, limitando a formação de trombo. Nessas condições, as células endoteliais podem se desenvolver a partir de tecidos que se projetam entre as hastes dos stents, desde que o endotélio não tenha sido totalmente desnudado ${ }^{22}$. A relação entre o grau de lesão na parede do vaso causado pelo stent e o grau de hiperplasia intimal tem sido demonstrada experimentalmente e em humanos ${ }^{26,27}$. Schwartz et al. demonstraram uma correlação muito próxima entre o grau de penetração das hastes dos stents nas camadas da parede do vaso e a proliferação intimal ${ }^{26}$. Sullivan et al. demonstraram que a permanência de uma lâmina elástica interna intacta é um importante fator na prevenção da hiperplasia intimal e reestenose, após implante de stent em artérias ilíacas ${ }^{28}$. Embora o infiltrado inflamatório tenha sido observado em vasos com ruptura da média e com as hastes dos stents no núcleo lipídico $^{29}$, alguns investigadores chamam a atenção para a contaminação por partículas do stent que produzem inflamação ${ }^{30}$. A liberação lenta de íons metais nos tecidos que circundam o local de implante do stent pode ser a razão da resposta inflamatória e hiperplásica local. Os produtos corrosivos das ligas de metal, comumente utilizados na fabricação de stents, (aço inoxidável $316 \mathrm{~L}$ e o nitinol) demonstram biotoxicidade ${ }^{19,31}$. O nitinol demonstrou ter efeito inflamatório por causar um aumento da secreção de interleucina-1 B pelos monóci$\operatorname{tos}^{32}$. A diminuição da concentração de níquel foi observada em áreas com falência estrutural devido à corrosão 
em endopróteses aórticas de nitinol. A falha estrutural dos stents maiores, sujeitos a uma força muito maior quando comparados a stents menores, pode estar relacionada à heterogeneidade focal e a inclusão de material, gerando corrosão galvânica e eventual fratura ${ }^{33}$.

O diâmetro das hastes dos stents também tem influência, pois stents com hastes maiores servem como obstáculo à migração celular. A densidade da malha do stent tem influência na resposta da hiperplasia intimal. Stents com poucas hastes colocadas longe umas das outras produzem mais hiperplasia intimal do que mais hastes em volta da circunferência, mesmo sendo uniformemente distribuídos. Isso tem relação com o alinhamento da parede do vaso com poucas hastes do stent que produz um lúmen poligonal ao invés de um lúmen circunferencial $^{34}$.

O sucesso de um implante de stent depende de uma mínima trombose e de uma rápida endotelização. Após a angioplastia, ocorre dissecção da íntima e da média com exposição dos elementos subintimais aos elementos da corrente sanguínea, trazendo como resultado a deposição de plaquetas e formação de trombo, a proliferação de fibroblastos e a hiperplasia intimal. No local da dissecção, o fluxo sanguíneo torna-se turbulento, devido à irregularidade da camada íntima, contribuindo para a deposição excessiva de plaquetas e fibri$\mathrm{na}^{35}$. Richter et al. mostraram a necessidade do uso de heparina para prevenção da trombose do stent e, também, que vasos de baixo fluxo estão mais sujeitos a uma taxa de reestenose maior ${ }^{36}$.

Robinson et al. estudaram a resposta celular de stents implantados em aorta e artérias ilíacas de coelhos. A microscopia óptica e a eletrônica revelaram que as células endoteliais e pseudo-endoteliais aderem à prótese logo no primeiro dia após o implante do stent ${ }^{37}$. Aparentemente, ocorre trombose localizada, levando a uma organização do trombo. As células musculares lisas e as células inflamatórias migram para o local do implante, levando à incorporação do stent na parede arterial. Uma camada endotelial confluente se regenera dentro de 2 a 4 semanas. O grau de hiperplasia tem sido relacionado com a evidência histológica de inflamação no vaso submetido a implante de stent. Infiltrados de neutrófilos são prevalentes poucos dias após o implante de stent ${ }^{27}$, e macrófagos e linfócitos predominam em 6 meses $^{29}$. Tem sido observada, porém, a formação de granuloma próximo à haste do stent independente do grau de lesão ${ }^{38}$.

Dolmatch demonstrou que, após vários dias, as células miointimais primitivas e as células inflamatórias (macrófagos e leucócitos polimorfonucleares) são vistas dentro do trombo ${ }^{21}$. O processo continua com a deposição de matriz do colágeno, a proliferação de células miointimais e o desenvolvimento de uma camada endotelial. Embora tal resposta esteja relacionada à exposição no momento do implante da endoprótese, não há razão para acreditar que esse processo seja diferente em outras endopróteses que são projetadas com a estrutura metálica por fora da malha de tecido e não expostas ao fluxo sanguíneo ${ }^{21}$.

A taxa de endotelização é influenciada mais pela migração do que pela proliferação celular. Um importante fator que afeta o grau de endotelização é a medida da velocidade de fluxo laminar. Em condições de fluxo normal, as células migram na direção do fluxo em direção única e mais rapidamente. Essa observação demonstra o fato de que na parede de artérias coronárias, após o implante de stent, com mínima lesão ao endotélio, a endotelização ocorre em poucos dias. Por outro lado, stents implantados em vasos ocluídos ou após largas lesões endoteliais, como em casos de uso de cateteres de endarterectomia ou revascularização a laser, o tempo de endotelização é estendido de muitas semanas a meses $^{25,39}$. A migração celular, a jusante, ocorre em um padrão de ziguezague e não em linha reta. Esse movimento aumenta a probabilidade de tais células se encontrarem com outras células que estão migrando e a sua colisão diminui a migração pela inibição por contato. Se uma célula migratória encontra um traço linear na superfície, assume esse padrão de migração ${ }^{39}$. Palmaz et al. demonstraram que a criação de ranhuras paralelas na superfície interna do stent em carótidas de suínos resulta em taxas de endotelização aceleradas 1 semana após o implante ${ }^{25}$.

Por sua grande força radial, os stents impedem que ocorram a retração elástica e o remodelamento negativo da parede do vaso, minimizando, dessa forma, dois dos principais mecanismos responsáveis pela perda do 
diâmetro do lúmen do vaso que ocorre após a angioplastia. Porém, apesar de os stents reduzirem de maneira significativa a incidência de reestenose, não foram capazes de solucionar integralmente o problema. Os stents permanecem indefinidamente no interior do vaso, estabelecendo uma complexa e duradoura interação com a parede vascular e com elementos da corrente sanguínea. Essa prótese combate o recolhimento elástico e o remodelamento negativo do vaso; perpetua, porém, o trauma à parede arterial e exerce forte estímulo à proliferação de tecido neo-intimal. A necessidade de diminuir a ocorrência de reestenose, após o implante de um stent, tem levado ao estudo de novos materiais para sua construção ou de substâncias para seu revestimento que reduzam o potencial trombogênico e evitem hiperplasia intimal. Basicamente, existem dois tipos de projetos visando minimizar a hiperplasia intimal: estudo sobre a estrutura de configuração do stent e sobre a associação de outras modalidades terapêuticas ao stent ${ }^{2,4,22,40}$.

A fixação do stent ao vaso se estabelece basicamente a partir do equilíbrio entre a resistência da parede e a força radial do stent. O contato íntimo desses metais com a parede vascular estabelece um caráter reacional local, que, ao longo do tempo, irá interferir na sua permeabilidade. Para diminuir tal tipo de alteração, foram desenvolvidas coberturas com soluções e películas (stents revestidos por carbono ou carbeto de silício, um material inerte de baixa trombogenicidade, que reduz a agregação plaquetária por inibir a migração dos elétrons para os metais). Esses stents possuem a vantagem de não inibir o crescimento do endotélio e de diminuir a reação inflamatória ${ }^{41}$. As vantagens e as limitações do material polimérico devem ser avaliadas por meio de suas propriedades biomecânicas e biológicas para a aplicação vascular. Um material ideal para implante deve ser resistente à trombose, estável mecanicamente e também facilmente incorporado pelo tecido, mas não incitar a resposta proliferativa, inflamatória ou degenerativa ${ }^{41}$. Por exemplo, a resistência à trombose e a reação tecidual são mais importantes em vasos de menor calibre, e a durabilidade é importante nos vasos de maior calibre ${ }^{36}$.

Os stents recobertos com politetrafluoretileno (PTFE), polietileno tereftalato (PET), poliéster $\left(\right.$ Dacron $^{\circledR}$ ), poliuretano, ligas de carbono, com drogas ou polímeros contendo drogas antitrombóticas e antiproliferativas têm sido investigados como alternativa no combate à hiperplasia intimal ${ }^{4}$.

O enxerto de PTFE é um material inerte com poros muito pequenos que limita o crescimento interno do tecido. Os stents revestidos de PTFE são indicados principalmente em estenoses longas, porém sua utilização é limitada em reestenoses refratárias e, também devem ser utilizados com cautela quando existem importantes vasos colaterais que, se forem cobertos, podem ocasionar a piora da isquemia do membro. Os resultados preliminares demonstram uma perviedade primária de $86 \%$ em 9 meses no tratamento de lesões longas da artéria femoral superficial ${ }^{42-44}$. Stents revestidos com PTFE foram testados em suínos, objetivando avaliar a capacidade de cicatrização, comparados a stents nãorevestidos. $\mathrm{O}$ resultado da perviedade foi igual nos dois grupos, porém o PTFE não impediu o espessamento progressivo neo-intimal. Alterações estruturais do PTFE, quando dilatado, podem estar relacionadas ao aumento da resposta inflamatória ${ }^{45-47}$.

O poliéster é manufaturado como arranjo de fibras $\left(\right.$ Dacron $\left.^{\circledR}\right)$. Por essa razão, tais materiais se apresentam como formas têxteis. As duas formas de fabricação são o woven e o knitted. O tipo knitted é mais flexível e maleável, particularmente quando manufaturado com pontes transversas. O tipo woven tem pouca elasticidade e tende a enrugar e dobrar facilmente, tendo dificuldade para assumir o contorno sinuoso e tubular dos vasos sanguíneos. A resposta biológica aos enxertos de Dacron $^{\circledR}$ é caracterizada por uma cápsula fibrosa que reveste a superfície externa da prótese e na microscopia observa-se abundante matriz extracelular que infiltra a malha do tecido. A superfície luminal é composta de material fibrinóide compactado, com ausência de células endoteliais, exceto nas áreas vizinhas da anastomose. O enxerto de Dacron ${ }^{\circledR}$, quando implantado em vasos de menor calibre, induz uma intensa reação celular composta de células do tipo "corpo estranho" e de camadas concêntricas de linfócitos e eosinófilos. Essa reação tecidual restringe a luz vascular, levando à trombose ${ }^{48,49}$.

Angelini et al. encontraram diminuição da hiperplasia intimal em enxertos de safena de porcos com hipercolesterolemia após a colocação de stents com 
revestimento de poliéster ${ }^{50}$. Castañeda et al. não encontraram diferença na espessura da íntima e da média ao comparar stents não-recobertos com os de revestimento de poliéster ${ }^{51}$. Marty et al. avaliaram a fixação de dois tipos de stents, um com revestimento de poliéster e outro com poliuretano, e concluiu que as próteses com poliuretano tiveram uma fixação mais extensa com tecido de granulação ${ }^{49}$. Avino et al. avaliaram a colocação de stents de nitinol revestidos com Dacron ${ }^{\circledR}$ em aorta de cães e concluíram que, apesar dos stents recobertos induzirem uma hiperplasia intimal maior, a área luminal não foi alterada ${ }^{52}$. Os autores não encontraram diferença na perviedade, na formação de trombos, na hemodinâmica de fluxo e na endotelização luminal. Resultado semelhante foi relatado por Dutra \& Pereira, em $2001^{53}$. Os enxertos de polietileno tendem a provocar aumento de trombogenicidade, quando comparados aos de PTFE, por induzirem um aumento da atividade pró-coagulante dos macrófagos ${ }^{49}$.

Em relação à incorporação dos stents pela parede vascular, a mais importante diferença entre os stents revestidos com materiais poliméricos e os stents nãorevestidos é que os stents não-revestidos têm maior tendência à endotelização, talvez relacionada à superfície favorável dos metais. Essas propriedades provavelmente determinam uma ligação estável com as proteínas, quando expostas ao fluxo sanguíneo, seguindo-se a fixação das células na malha metálica dos stents. Os stents revestidos são menos biocompatíveis ${ }^{22,47,48}$.

O silicone também foi estudado devido a sua propriedade elástica e durabilidade. Fontaine et al. compararam em cães os efeitos biológicos de stents revestidos com silicone aos stents não-revestidos, e concluiu que a membrana permaneceu inerte após 6 semanas, sem ocorrência de trombose e mínima hiperplasia intimal ${ }^{54}$. Galloni et al. realizaram experimento com stent revestido de liga de carbono, que mostrou boa compatibilidade tecidual e hematológica, e nenhum caso de trombose foi registrado ${ }^{55}$.

Além do revestimento com enxerto, substâncias podem ser impregnadas com o objetivo de reduzir a reação do enxerto e obter a endotelização com maior rapidez. A compreensão da fisiopatologia da reestenose dos stents fez reacender o interesse pelo uso de agentes antiproliferativos. Todavia, alguns fatores são necessários para a utilização clínica de stents com drogas antiproliferativas como, por exemplo, uma matriz biologicamente inerte, fisiologicamente sólida e deformável. A matriz deve ser rígida o bastante para resistir às demandas fisiológicas da organização, sem sofrer rachaduras ou delaminações, e também deve sobreviver ao processo de esterilização sem alterar suas propriedades. Outro fator é o tempo correto de liberação da droga, limitado a 6 semanas ou menos ${ }^{4}$.

A fixação segura da droga ao stent é muito importante e os mecanismos (com muitas variações e combinações) para tal são: 1) fixação direta; 2) fixação por meio de poros revestidos; ou 3) por meio de revestimentos dissolvíveis, nos quais a droga é misturada, sendo liberada pela dissolução do revestimento ou por quebra enzimática das substâncias que se ligam às drogas. Também tem importância uma geometria favorável para a liberação da droga, sendo que, geralmente, quanto maior o tamanho da célula mais heterogêneo é o local de liberação ${ }^{4}$.

Recentemente, a divulgação dos resultados preliminares do uso de stents recobertos com a rapamicina (sirolimus) tem trazido grande entusiasmo, pela perspectiva de redução expressiva na incidência de reestenose. A rapamicina foi originalmente desenvolvida como droga antifúngica, mas sua utilidade foi questionada devido aos efeitos imunossupressores. Em 1999, foi aprovada pelo FDA para utilização como droga em pacientes com rejeição ao transplante renal. Em estudos sobre transplantes cardíacos, foi descoberta uma inibição da proliferação miointimal, tornando a rapamicina o alvo principal de trabalhos sobre stents revestidos com drogas antiproliferativas ${ }^{56,57}$. A rapamicina age inibindo a fase G1 a S do ciclo celular através da proteína de ligação tacrolimus (FK506), ligando-se assim a uma molécula chamada mTOR (mammalian target of rapamycin), inibindo a sua ativação ${ }^{4}$.

Apesar de os trabalhos iniciais serem bastante animadores, o estudo "Sirius" não demonstrou resultados muito satisfatórios ao avaliar o implante de stents revestidos com rapamicina em artérias coronárias de pacientes com dados clínicos mais complexos, incluindo os 
diabéticos. Um interesse especial esteve relacionado a um potencial aumentado de trombose tardia e, apesar da diminuição da hiperplasia intimal, ocorreu a hipótese de retardo no processo de endotelização. Os estudos Sirocco I e II avaliaram os resultados do implante de stents auto-expansíveis com rapamicina em pacientes portadores de isquemia crônica de membro inferior, devido à lesão da artéria femoral superficial. Os resultados não demonstraram diferença estatística entre os grupos, sendo que nesse tipo de artéria, a principal causa de falência dos stents estaria relacionada a fatores mecânicos com conseqüente fratura dos stents em longo pra$\mathrm{zo}^{58,59}$. Por exemplo, stents de nitinol podem apresentar fratura relacionada à cobertura e ao polimento com óxidos amorfos ${ }^{19,20}$.

A análise de vários estudos em diferentes leitos vasculares tende a mostrar que artérias de pequeno calibre estão mais sujeitas a hiperplasia intimal e a reações celulares da interação stent/parede do vaso e as artérias de maior calibre estão sujeitas a fatores estruturais e mecânicos tanto do stent como da parede do vaso envolvi$\mathrm{do}^{60}$. A própria estrutura dos stents tem importância na prevenção da oclusão ou reestenose, sendo baseada em diversos fatores, como: o mecanismo de liberação, o material de fabricação, a geometria dos stents, a presença de polímeros e/ou outras substâncias capazes de induzir inflamação local e outros fatores mecânicos ${ }^{61-63}$. As diferenças entre modelos de stents são confirmadas por diversos autores em estudos com animais experimentais $^{34,64}$ e em séries clínicas ${ }^{9,63}$. Os resultados favoráveis crescem na medida em que o entendimento das reações envolvidas na interação do stent com a parede dos vasos sanguíneos aumenta e, também, devido ao constante avanço tecnológico dos materiais utilizados ${ }^{62,65,66}$.

Outro medicamento também analisado é o paclitaxel, um agente antiproliferativo, citostático e quimioterápico que previne a migração de células musculares lisas, funciona como agente estabilizador microtubular e estimula a apoptose ou a morte celular programada. O paclitaxel também possui efeitos antiinflamatórios ${ }^{67}$. As drogas que inibem as reações, antes da fase $\mathrm{S}$, têm tendência à inibição do crescimento celular, e aquelas que inibem as porções tardias do ciclo tendem a ser mais tóxicas. O sirolimus e o everolimus agem interrompendo a transição da fase G1 para a fase S do ciclo celular. Em comparação com o paclitaxel, este age mais tardiamente no estágio de mitose inibindo a função microtubular ${ }^{4}$.

Fontaine et al. demonstraram em cães que a absorção e a eluição do abciximab da superfície de um stent recoberto é viável e que a liberação local dessa droga reduziu o espessamento miointimal ${ }^{68}$. Contudo, Ansel et al., em estudo denominado BLASTER (Bilateral Lower Arterial Stenting Employing Reopro), não encontraram diferença na utilização do abciximab com os resultados de perviedade de stents auto-expansíveis de nitinol em artérias femorais ${ }^{69}$.

Não existe evidência de estudos em animais experimentais para afirmar o quanto e por quanto tempo a substância deve ficar no tecido até que o complexo stent /parede do vaso desenvolva uma fina camada neointimal e se torne mecanicamente estável. Esse pode nunca se tornar estável. Assim, talvez uma pequena dose da substância liberada por um período longo de tempo possa retardar o crescimento do tecido, aumentando a durabilidade do stent, mas nunca estabilizando o complexo stent/parede do vaso. Ao estudar os efeitos da homocisteína após o implante de stent em modelo experimental, os autores demonstraram que ocorre menos hiperplasia intimal em aorta de suínos com hiperhomocisteinemia, o que sugere possível interação da homocisteína com o desenvolvimento da hiperplasia intimal ${ }^{70}$.

Os stents podem ser revestidos com substâncias que criam uma superfície não-detectável pelo organismo, e, assim, não causam reações. Dentre essas substâncias, pode-se citar o colágeno, a fibrina, a heparina, a fosforilcolina e várias moléculas bioativas ${ }^{4}$. Cloft et al. obtiveram resultados favoráveis observando rápida endotelização e baixa estenose reativa, após o implante de stents revestidos com colágeno bovino tipo I em aorta de coelhos $^{71}$.

A heparina é um proteoglicano que inibe a proliferação de células musculares lisas in vitro. Vários trabalhos têm demonstrado que a expressão de moléculas de adesão está diminuída em pacientes com stents revestidos com fosforilcolina e heparina. O efeito inibidor é 
mediado em parte pelas interações com receptores celulares, fatores de crescimento, moléculas de adesão e inibidores das proteinases. Devido às propriedades antiproliferativas e anticoagulantes, muitas pesquisas foram realizadas para determinar qual a melhor estratégia para a administração da heparina, após a colocação do stent, na tentativa de se evitar a hiperplasia intimal. Lin et al. demonstraram em primatas que stents recobertos com heparina por meio de ligação covalente induzem uma hiperplasia intimal menor em relação ao grupo controle ${ }^{72,73}$. Nakayama et al. estudaram stents revestidos com heparina e FK506. A heparina revestiu a face interna, ou seja, o lúmen do stent em contato com a corrente sanguínea (devido às suas propriedades anticoagulantes) e o FK506 revestiu a face externa em contato com a parede do vaso (devido a sua ação imunossupressora). A conclusão foi que esse tipo de revestimento foi efetivo na prevenção da hiperplasia intimal $^{74}$.

As metaloproteases são moléculas da família das proteases dependentes de zinco e cálcio, que degradam o colágeno e outras proteínas da matriz, como a elastina e os proteoglicanos. A lesão vascular resulta em padrões temporais de aumento da atividade das metaloproteinases. Tais enzimas, além de estarem relacionadas ao remodelamento vascular e à hiperplasia intimal, pelo seu efeito sobre a proliferação e a migração celular, também têm efeitos na inflamação e na angiogênese. Assim, hipoteticamente, a inibição dessas enzimas resultaria em redução da hiperplasia intimal. Entretanto, Van Beusekom et al., ao estudarem os efeitos do batimastat, um inibidor inespecífico das metaloproteinases e, também, uma droga antineoplásica e com propriedades antiangiogênicas, não encontraram influência significativa na reação neo-intimal após a colocação de stent em artérias femorais de porcos, apesar de existirem trabalhos em animais que comprovaram seus efeitos de diminuição do remodelamento da parede do vaso após angioplastia transluminal percutânea ${ }^{75}$.

A radioterapia intra-arterial é outra modalidade terapêutica que tem sido amplamente estudada, objetivando a supressão de genes envolvidos no controle do ciclo de proliferação celular. Ela age através do bombardeio do núcleo celular com radiação ionizante, e produz a quebra das duas hélices que compõem o DNA. Dessa maneira, bloqueia sua duplicação, que é condição fundamental para a proliferação celular. Com as doses de radiação recomendadas, as células lisas permanecem viáveis, porém impossibilitadas de se replicar. Vários autores demonstraram experimentalmente a eficácia da radiação gama utilizando irídio ${ }^{192}$, para inibir a proliferação da neo-íntima ${ }^{76-78}$. O único estudo em humanos, publicado até o momento, utiliza irídio para inibir a proliferação da neo-íntima em artérias periféricas. Em seres humanos, os resultados dos primeiros estudos clínicos divulgados são animadores. Entretanto, as tromboses tardias e as reestenoses de bordas ainda limitam sua aplicação. O estudo Vienna-5 trial, que avaliou a efetividade da braquiterapia na prevenção da reestenose após implante de stent em artérias femorais de 88 pacientes, concluiu, depois de 12 meses, não ter sido efetiva essa terapia para a manutenção da perviedade em 6 meses $^{79}$. Outro estudo, denominado Paris trial, também não demonstrou benefício do uso da braquiterapia para o tratamento da reestenose ${ }^{80}$. Algumas questões ainda estão sem resposta sobre a utilização da radioterapia em cirurgia endovascular, como por exemplo: qual a dose efetiva recomendada? A radiação deve ser administrada antes ou após a angioplastia? Qual a radiação deve ser utilizada - beta, gama? Qual modo de liberação de radiação é o mais efetivo - cateter, balão ou stent? A radiação realmente tem efeito benéfico na prevenção da reestenose $\operatorname{tardia}{ }^{79,80}$ ?

Concluindo, a cirurgia endovascular é uma especialidade que oferece uma opção minimamente invasiva para o tratamento das patologias vasculares periféricas. Com o crescente desenvolvimento da tecnologia e o avanço das pesquisas para encontrar um substituto vascular ideal, o uso dos stents, tornou-se uma opção terapêutica promissora. Contudo, a utilização dos stents não está isenta de complicações (fraturas, hiperplasia intimal, etc.), e o conhecimento da correta utilização das diversas endopróteses disponíveis no mercado é essencial para a obtenção de resultados favoráveis.

\section{Referências}

1. Lobato AC. Stents vasculares. In: Lobato AC. Cirurgia endovascular. São Paulo: Instituto de Cirurgia Vascular e Endovascular de São Paulo; 2006. p. 83-96. 
2. Puech-Leão P. Angioplastia transluminal percutânea. In: Carnevale FC. Radiologia intervencionista e cirurgia endovascular. Rio de Janeiro: Revinter; 2006. p. 117-21.

3. Schneider PA. Stents. Endovascular repaving. In: Endovascular skills: guidewire and catheter skills for endovascular surgery. 2nd ed. New York: Marcel Dekker; 2003.

4. Nelken N, Schneider PA. Advances in stent technology and drug-eluting stents. Surg Clin North Am. 2004;84:1203-36.

5. Leung DA, Spinosa DJ, Hagspiel KD, Angle JF, Matsumoto AH. Selection of stents for treating iliac arterial occlusive disease. J Vasc Interv Radiol. 2003;14:137-52.

6. Chuapetcharasopon C, Wright KC, Wallace S, Dobben RL, Gianturco C. Treatment of experimentally induced atherosclerosis in swine iliac arteries: a comparison of self-expanding and balloon-expanded stents. Cardiovasc Intervent Radiol. 1992;15:143-50.

7. Mangell P, Malina M, Vogt K, et al. Are self-expanding stents superior to balloon-expanded in dilating aortas? An experimental study in pigs. Eur J Vasc Endovasc Surg. 1996;12:287-94.

8. Andrews RT, Venbrux AC, Magee CA, Bova DA. Placement of a flexible endovascular stent across the femoral joint: an in vivo study in the swine model. J Vasc Interv Radiol. 1999;10:1219-28.

9. Henry M, Klonaris C, Amor M, Henry I, Tzvetanov K. State of the art: which stent for which lesion in peripheral interventions? Tex Heart Inst J. 2000;27:119-26.

10. Moreira AM. Materiais. In: Carnevale FC. Radiologia intervencionista e cirurgia endovascular. Rio de Janeiro: Revinter; 2006. p. 33-55.

11. Schatz RA, Baim DS, Leon M, et al. Clinical experience with the Palmaz-Schatz coronary stent. Initial results of a multicenter study. Circulation. 1991;83:148-61.

12. Rousseau H, Joffre J, Puel J, et al. Percutaneous vascular stent: experimental studies and preliminary clinical results in peripheral arterial diseases. Int Angiol. 1987;6:153-61.

13. Rolland PH, Mekkaoui C, Vidal V, et al. Compliance matching stent placement in the carotid artery of the swine promotes optimal blood flow and attenuates restenosis. Eur J Vasc Endovasc Surg. 2004;28:431-8.

14. Jahnke T, Voshage G, Müller-Hülsbeck S, Grimm J, Heller M, Brossmann J. Endovascular placement of self-expanding nitinol coil stents for the treatment of femoro-popliteal obstructive disease. J Vasc Interv Radiol. 2002;13:257-66.

15. Bosiers M, Deloose K, Verbist J, Peeters P. Carotid artery stenting: which stent for which lesion? Vascular. 2005;13:205-10.

16. Dyet JF, Schurmann K. The physical and biological properties of metallic stents. In: Dyet JF, Ettles DF, Nicholson AA, Wilson SE. Textbook of endovascular procedures. Philadelphia: Churchill Livingstone; 2000. p. 15-26.

17. Gotman I. Characteristics of metals used in implants. J Endourol. 1997;11:383-9.

18. Barras CD, Myers KA. Nitinol - its use in vascular surgery and other applications. Eur J Vasc Endovasc Surg. 2000;19:564-9.
19. Shih CC, Lin SJ, Chen YL, et al. The cytotoxicity of corrosion products of nitinol stent wire on cultured smooth muscle cells. J Biomed Mater Res. 2000;52:395-403.

20. Riepe G, Heintz C, Kaiser E, et al. What can we learn from explanted endovascular devices? Eur J Vasc Endovasc Surg. 2002;24:117-22.

21. Dolmatch BL. Healing response to vascular stent-grafts. J Vasc Surg. 2000;31:1285-9.

22. Palmaz, JC. Intravascular stents: tissue stent interactions and design considerations. ARJ Am J Roentgenol. 1993;160:613-8.

23. Pisco JM, Correia M, Esperança-Pina JA, de Sousa LA. Vasa vasorum changes following stent placement in experimental arterial stenoses. J Vasc Intervent Radiol. 1993;4:269-73.

24. Schatz RA. A view of vascular stents. Circulation. 1989;79:445-57.

25. Palmaz JC, Tio FO, Schatz RA, Alvarado R, Rees C, Garcia FS. Early endothelialization of balloon-expandable stents: experimental observations. J Intervent Radiol. 1988;3:119-24.

26. Schwartz RS, Huber KC, Murphy JG, et al. Restenosis and the proportional neointimal response to coronary artery: results in a porcine model. J Am Coll Cardiol. 1992;19:267-74.

27. Farb A, Sangiorgi G, Carter AJ, et al. Pathology of acute and chronic coronary stenting in humans. Circulation. 1999;99:44-52.

28. Sullivan TM, Ainsworth SD, Langan EM, et al. Effect of endovascular stent strut geometry on vascular injury, myointimal hyperplasia, and restenosis. J Vasc Surg. 2002;36:143-9.

29. Farb A, Weber DK, Kolodgie FD, Burke AP, Virmani R. Morphological predictors of restenosis after coronary stenting in humans. Circulation. 2002;105:2974-80.

30. Bayes-Genis A, Kantor B, Keelan PC, et al. Reestenosis and hyperplasia: animal models. Curr Interv Cardiol Rep. 2000;2:303-8.

31. Palmaz JC, Bailey S, Marton D, Sprague E. Influence of stent design and material composition on procedure outcome. J Vasc Surg. 2002;36:1031-9.

32. Wataha JC, Lockwood PE, Marek M, Ghazi M. Ability of Ni-containing biomedical alloys to activate monocytes and endothelial cells in vitro. J Biomed Mater Res. 1999;45:251-7.

33. Heintz C, Riepe G, Birken L. Corroded nitinol wires in explanted aortic endografts: an important mechanism of failure? J Endovasc Ther. 2001;8:248-53.

34. Garasic JM, Edelman ER, Squire JC, Seifert P, Williams MS, Rogers C. Stent and artery geometry determine intimal thickening independent of arterial injury. Circulation. 2000;101:812-8.

35. Faxon DP, Sanborn TA, Weber VJ, et al. Restenosis following transluminal angioplasty in experimental atherosclerosis. Arteriosclerosis. 1984;4:189-95.

36. Richter GM, Palmaz JC, Noeldge G, Tio F. Relationship between blood flow, thrombus, and neointima in stents. J Vasc Interv Radiol. 1999;10:598-604.

37. Robinson KA, Roubin G, King S, Siegel R, Rodgers G, Apkarian RP. Correlated microscopic observations of arterial responses to intravascular stenting. Scannig Microsc. 1989;3:665-72. 
38. Kornowski R, Mintz GS, Kent KM, et al. Increased restenosis in diabetes mellitus after coronary interventions is due to exaggerated intimal hyperplasia. A serial intravascular ultrasound study. Circulation. 1997;95:1366-9.

39. Hamuro M, Palmaz JC, Sprague EA, Fuss C, Luo J. Influence of stent edge angle on endothelialization in an in vitro model. J Vasc Interv Radiol. 2001;12:607-11.

40. Junior JF, Jacques NMP. Próteses endovasculares (stents). In: Maffei FHA, Lastória S, Yoshida WB, Rollo HA. Doenças vasculares periféricas. $3^{\text {a }}$ ed. Rio de Janeiro: Medsi; 2002. p. 871-89.

41. Palmaz JC. New advances in endovascular technology. Tex Heart Inst J. 1997;24:156-9.

42. Lammer J, Dake MD, Bleyn J, et al. Peripheral arterial obstruction: prospective study of treatment with a transluminally placed self-expanding stent-graft. International Trial Study Group. Radiology. 2000; 217:95-104.

43. Lammer J. Femoropopliteal artery obstruction: from the balloon to the stent graft. Cardiovasc Intervent Radiol. 2001;24:73-83.

44. Wiesinger B, Beregi JP, Oliva VL, et al. PTFE-covered self-expanding nitinol stents for the treatment of severe iliac and femoral artery stenoses and occlusions: final results from a prospective study. J Endovasc Ther. 2005;12:240-6.

45. Grudtner MA, Pereira AH, Costa LFM, et al. Efeitos a curto prazo de "stents" não recobertos e recobertos com politetrafluoretileno em aorta de suínos: um modelo experimental. Acta Cir Bras. 2004;19:126-30.

46. Ombrellaro MP, Stevens SL, Sciarrotta J, Schaeffer DO, Freeman MB, Goldman MH. Effect of ballon-expandable and self expanding stent fixation on endoluminal polytetrafluoroethylene graft healing. Am J Surg. 1997;173:461-6.

47. Cejna M, Virmani R, Jones R, et al. Biocompatibility and performance of the wallstent and several covered stents in a sheep iliac artery model. J Vasc Interv Radiol. 2001;12:351-8.

48. Pasquinelli G, Freyrie A, Preda P, Curti T, D'Addato M, Laschi R. Healing of prosthetic arterial grafts. (Review). Scanning Microsc. 1990;4:351-62.

49. Marty B, Leu AJ, Mucciolo A, von Segesser LK. Biologic fixation of polyester- versus polyurethane-covered stents in a porcine model. J Vasc Interv Radiol. 2002;13:601-7.

50. Angelini GD, Lloyd C, Bush R, Johnson J, Newby AC. An external, oversized, porous polyester stent reduces vein graft neointima formation, cholesterol concentration, and vascular cell adhesion molecule 1 expression in cholesterol-fed pigs. $\mathbf{J}$ Thorac Cardiovasc Surg. 2002;124:950-56.

51. Castañeda F, Ball SM, Wyffels PL, Young K, Li R. Assesment of a polyester covered nitinol stent in an atherosclerotic swine model. J Vasc Interv Radiol. 2000;11:483-91.

52. Avino A, Johnson B, Bandyk D, et al. Does prosthetic covering of nitinol stents alter healing characteristics or hemodynamics? J Endovasc Ther. 2000;7:469-78.

53. Dutra CF, Pereira AH. Digital morphometric analysis of the aortic wall in pigs following implantation of dacron-covered stents versus non-covered stents. Acta Cir. Bras. [serial online] 2004; 19:210-9.
54. Fontaine AB, Borsa JJ, Hoffer E, Bloch R, So C. Evaluation of silicone as an endovascular stent membrane: in vivo canine studies. Cardiovasc Interv Radiol. 2001; 24:324-8.

55. Galloni M, Prunotto M, Santarelli A, et al. Carbon coated stents implanted in porcine iliac and renal arteries: histologic and histomorphometric study. J Vasc Interv Radiol. 2003; 14:1053-61.

56. Goggins WC, Fisher RA, Cohen DS, Tawes JW, Grimes MM. Effect of single-dose rapamycin-based immunosuppression on the development of cardiac allograft vasculopathy. J Heart Lung Transplant. 1996;15:790-5.

57. Moses JW, Leon MB, Popma JJ. Sirolimus-eluting stents versus standard stents in patients with stenosis in a native coronary artery. N Engl J Med. 2003;349:1315-23.

58. Duda SH, Bosiers M, Lammer J. Drug-eluting and bare nitinol stents for the treatment of atherosclerotic lesions in the superficial femoral artery: long-term results from the SIROCCO trial. J Endovasc Ther. 2006;13:701-10.

59. Duda SH, Bosiers M, Lammer J, et al. Sirolimus-eluting versus bare nitinol stent for obstructive superficial femoral artery disease: the SIROCCO II trial. J Vasc Interv Radiol. 2005; 16:331-8.

60. Krueger KD, Mitra AK, DelCore MG, Hunter WJ 3rd, Agrawal DK. A comparison of stent-induced stenosis in coronary and peripheral arteries. J Clin Pathol. 2006;59:575-9.

61. Wolosker N, Nakano L, Anacleto MM, Puech-Leão P. Primary utilization of stents in angioplasty of superficial femoral artery. Vascular and Endovascular Surg. 2003;37:271-7.

62. Mewissen, MW. Self-expanding nitinol stents in the femoropopliteal segment: technique and mid-term results. Tech Vasc Interv Radiol. 2004;7:2-5.

63. Scheinert D, Scheinert S, Sax J, et al. Prevalence and clinical impact of stent fractures after femoropopliteal stenting. J Am Coll Cardiol. 2005;45:312-5.

64. Rogers C, Edelman ER. Endovascular stent design dictates experimental restenosis and thrombosis. Circulation. 1995;91:2995-3001.

65. Sabeti S, Czerwenka-Wenkstetten A, Dick P, et al. Quality of life after balloon angioplasty versus stent implantation in the superficial femoral artery: findings from a randomized controlled trial. J Endovasc Ther. 2007;14:431-7.

66. Schillinger M, Sabeti S, Dick P, et al. Sustained benefit at 2 years of primary femoropopliteal stenting compared with balloon angioplasty with optional stenting. Circulation. 2007;115:2745-9.

67. Park SJ, Shim WH, Ho DS, et al. A paclitaxel-eluting stent for the prevention of coronary restenosis. N Engl J Med. 2003;348:1537-45

68. Fontaine AB, Borsa JJ, Dos Passos S, et al. Evaluation of local abciximab delivery from the suface of a polymer-coated covered stent: in vivo canine studies. J Vasc Interv Radiol. 2001;12:487-92.

69. Ansel GM, Silver MJ, Botti CF Jr., et al. Functional and clinical outcomes of nitinol stenting with and without abciximab for complex superficial femoral artery disease: a randomized trial. Catheter Cardiovasc Interv. 2006;67:288-97. 
70. França LH, Pereira AH, Perini SC. Self-expandable nitinol stent placement in homocysteneimic porcine aorta. Clinics. 2008;63:229-36.

71. Cloft HJ, Kallmes DF, Lin HB, et al. Bovine type I collagen as an endovascular stent-graft material: biocompatibility study in rabbits. Radiology. 2000;214:557-62.

72. Lin PH, Chronos NA, Marijianowski MM, et al. Carotid stenting using heparin-coated balloon-expandable stent reduces intimal hyperplasia in a baboon model. J Surg Res. 2003;112:84-90.

73. Lin PH, Chronos NA, Marijianowski MM, et al. Heparin-coated balloon-expandable stent reduces intimal hyperplasia in the iliac artery in baboons. J Vasc Interv Radiol. 2003;14:603-11.

74. Nakayama Y, Nishi S, Ishibashi-Ueda H. Fabrication of drug-eluting covered stents with micropores and differential coating of heparin and FK506. Cardiovasc Radiat Med. 2003;4:77-82.

75. Van Beusekom HMM, Post MJ, Whelan DM, et al. Metalloproteinase inhibition by batimastat does not reduce neointimal thickening in stented atherosclerotic porcine femoral arteries. Cardiovasc Rad Med. 2003;4:186-91.

76. Shimotakahara S, Mayberg MR. Gamma irradiation in-hibits neointimal hyperplasia in rats after arterial injury. Stroke. 1994;25:424-8.
77. Wiedermann JG, Marboe C, Schwartz A, Amols H, Weinberg J. Intracoronary irradiation reduces restenosis after ballon angioplasty in porcine model. J Am Coll Cardiol. 1994; 23:1491-8.

78. Waksman R, Robinson KA, Crocker IR, Gravanis MB, Cipolla GD, King SB 3rd. Endovascular low-dose irradiation inhibits neointima formation after coronary artery balloon injury in swine: a possible role for radiation therapy in restenosis prevention. Circulation. 1995;91:1533-9.

79. Wolfram RM, Budinsky AC, Pokrajac B, Pötter R, Minar E. Vascular Brachytherapy with 192Ir after femoropopliteal stent implantation in high-risk patients: Twelve-month follow-up results from the Vienna-5 trial. Radiology. 2005;236:343-51.

80. Waksman R, Laird JR, Jurkovitz CT, et al. Intravascular radiation therapy after balloon angioplasty of narrowed femoropopliteal arteries to prevent restenosis: results of the PARIS feasibility clinical trial. J Vasc Interv Radiol. 2001;12:915-21.

Correspondência:

Luís Henrique Gil França

Rua Coronel Dulcídio, 1189/1801

CEP 80250-100 - Curitiba, PR

Tel.: (41) 3343.0963

E-mail: luishgf@hotmail.com 